\title{
Computer Professionals and Carpal Tunnel Syndrome (CTS)
}

\author{
K. Mohamed Ali \\ B.W.C. Sathiyasekaran \\ Department of Community Medicine, Sri Ramachandra Medical College \& Research Institute, \\ Porur, Chennai (Madras), India
}

Carpal Tunnel Syndrome (CTS) is an important problem among computer professionals. Hence the prevalence of CTS among computer professionals and risk factors were studied. 648 subjects were selected from 4,276 computer professionals from 21 companies with a simple random sampling method. CTS was diagnosed based on clinical features.

The prevalence of CTS was found to be $13.1 \%$ (95\% CI 10.5-15.7\%). Subjects with over 8 years of computer work, over 12 hrs of work per day and system administrators were at a higher risk for CTS (OR 3.3, 4.9 and 2.5 respectively). Flexed or extended hand position had higher risk for CTS.

Higher risk for CTS was found with higher exposure to computer work. Ergonomic considerations are important in facilitating proper positioning of hand while working with a computer. Further studies on CTS risk factors among computer professionals are essential for planning prevention.

musculoskeletal disorders cross-sectional study occupational disorder Tinel's sign Phalen's sign wrist hand Body Mass Index

\section{INTRODUCTION}

As computers are used in office automation throughout the world, for the past few decades a rapidly increasing work force has been involved with computers for increasing periods of time. Several studies have reported positive association between computer use and musculoskeletal symptoms $[1,2,3,4,5,6]$. Postural stress due to poor workstation ergonomics such as inappropriate location of the monitor, keyboard or mouse have been found to be associated with musculoskeletal problems $[7,8,9,10,11,12]$. Work organizational factors such as work pressure, project deadlines and lack of job security or decision-making opportunities also contribute to work-related musculoskeletal complaints [13, 14, 15].

Among musculoskeletal disorders, carpal tunnel syndrome (CTS) is commonly reported in computer professionals. Trauma caused by repetitive hand motion has been identified as an aggravating factor for CTS especially in persons whose work requires repeated forceful finger and wrist flexion and extension. The incidence of CTS has been reported to be high among those working with vibrating machinery and among office workers, especially typists and data entry clerks [16]. South Texas Veterans Health Care System in San Antonio, TX, USA, has reported CTS as a common computer-related illness in a significant portion of the American population [17]. A study done among female visual display terminal (VDT) operators, who were engaged in data entry for about 6 hrs a day, has reported a high prevalence of subclinical CTS [18]. In a survey of employees who were identified as frequent computer users, $29.6 \%$ reported hand par aesthesia and $10.5 \%$ met clinical criteria for CTS [19].

We thank the colleagues in the Department of Community Medicine, Sri Ramachandra Medical College \& Research Institute, Deemed University, Chennai, for all their encouragement. This study had no specific funding source.

Correspondence and requests for offprints should be sent to K. Mohamed Ali, Department of Community Medicine, Sri Ramachandra Medical College \& Research Institute, Porur, Chennai (Madras) - 600 116, India. E-mail: <lkbkma@yahoo.com>. 
CTS is defined as a complex of symptoms resulting from compression of the median nerve at the carpal tunnel [20]. Symptoms of median nerve compression include pain, numbness or tingling on the anterior surface of the index, middle or radial half of the ring finger. It is often associated with weakness of handgrip or nocturnal symptoms including hand or arm pain and numbness. Provocative physical examination techniques such as Tinel's sign, Phalen's sign, and two point discrimination tests have been used for the clinical diagnosis of this condition [21].

Like in many other countries in the world, in India the software market has shown an upward surge. As a result a large number of persons are involved in the computer profession there. Though computer-related health problems have been documented in other countries, not much information is available in India. In view of this, a cross-sectional study was taken up to estimate the prevalence of CTS among computer professionals in Chennai (Madras), one of the metropolitan cities in India. The other aim of the study was to evaluate the association between certain computer work-related factors (years of computer work, hours of computer work per day, type of computer job function, positioning of hand, etc.) and CTS.

\section{METHODS}

This cross-sectional study was done in a large computer facility office complex in Chennai where about 7,000 computer professionals of varying years of work experience were employed. Out of the 33 companies available, permission for the study could be obtained only from 21 companies. The common reasons given for the refusal were tight time schedule of work and inability to allot time for the study.

A list of all the employees in the 21 companies who gave permission for the study was obtained. There were 4,276 employees in total. Each employee was given a unique continuous identification number-between 1 and 4,276covering all the companies, one after the other. Then using a random number table, 648 employees were selected with simple random sampling as subjects for the study.

The selected computer professionals were contacted initially and informed consent was obtained. The criteria for inclusion in the study was experience for a continuous period of at least 6 months as a computer professional immediately before the selection for the study. Since all the 648 persons selected had more than 6 months of experience and since no one refused to take part in the study the total sample for the study remained at 648 .

Since it was planned to study a wide range of computer professionals and to estimate risk for CTS in different groups like males, females, different age groups, different years of exposure to the computer profession, different hours of computer work per day and different job types in the computer profession, no other specific criteria for selection of subjects were used except that the person had been a computer professional for at least 6 months.

The questionnaire used in the study was developed by the authors and included sociodemographic details and information about years of computer work, hours of computer work per day, computer job function, smoking habit, use of alcohol, Internet use (leisure time) and co-morbid conditions. The study participants were requested to demonstrate how they normally kept their hands while working with computers. By carefully observing this, the first author, who is also a medical doctor, recorded in the questionnaire if the hand was normally kept in a flexed, extended or neutral position. A neutral position refers to the lower arm and hand kept in a straight line without flexion or extension at the wrist and without radial or ulnar deviation.

Height and weight were measured and Body Mass Index (BMI) calculated. Study participants were considered as overweight if the BMI was $\geq 25$. Participants were asked whether they had pain or numbness on the anterior surface of the index, middle or radial half of the ring finger for the past week as a clinical symptom of CTS. Any 
person who had these clinical symptoms for CTS and was positive for either Tinel's or Phalen's sign was diagnosed as having CTS [21].

Tinel's sign was elicited by allowing the flat end of a triangular reflex hammer (knee hammer) to fall onto distal wrist crease from a distance of one handle $(20 \mathrm{~cm})$ above the wrist. Tinel's sign was considered positive if pain or par aesthesia was elicited or accentuated along the median nerve distribution. Phalen's test was elicited by asking the subjects to rest their elbows on a table with the forearms perpendicular to the surface and to flex the wrists down and away from the body for a period of $60 \mathrm{~s}$. Phalen's sign was considered positive if par aesthesia was elicited in the median nerve distribution [21].

\section{STATISTICAL ANALYSIS}

Descriptive analysis was done for the prevalence of CTS, with 95\% CI. Univariate logistic regression was done to find out the association between CTS and the risk factors. OR and 95\% CI were obtained. Adjusted OR was found by multiple logistic regression.

\section{RESULTS}

The total number of computer professionals studied was $648 ; 81.9 \%$ were males. The overall mean age was 25 years and 4 months, ranging from 20 to 51 years. The younger age group (20-30 years) comprised of $93.2 \%$ of males. All of them had formal training in computers $(52.7 \%$ of them had undergraduate or postgraduate qualification in computers). Smokers were $25.8 \%$, those taking alcohol at least once a week were $23.9 \%$ and $29.7 \%$ had BMI $\geq 25$. History of diabetes mellitus was given by $0.3 \%$, rheumatoid arthritis by $1.4 \%$ and thyroid disorders by $2 \%$ of the subjects. Among the subjects $54.2 \%$ were using internet during their leisure time (apart from their regular working schedule) (Table 1).
TABLE 1. Distribution of Gender and Age

\begin{tabular}{lccc}
\hline Age & Male & Female & Total (\%) \\
\hline 30 years & 491 & 113 & 604 \\
& & & $(93.2)$ \\
>30 years & 40 & 4 & 44 \\
& & & $(6.8)$ \\
Total $(\%)$ & 531 & 117 & 648 \\
& $(81.9)$ & $(18.1)$ & $(100)$ \\
\hline
\end{tabular}

The most common job function was data entry (37.7\%); $7.7 \%$ were system administrators. Among males $8.9 \%$ were system administrators compared to $2.6 \%$ among females. Overall mean years of computer work was 3 years and 10 months ranging from 8 months to 20 years. Among males $37.5 \%$ had 4 and more than 4 years of computer work compared to $15.4 \%$ among females. Overall mean hours of computer work per day were $9 \mathrm{hrs}$ ranging from 3.5 to $16 \mathrm{hrs}$. Among males $87 \%$ had $8 \mathrm{hrs}$ or more of computer work per day compared to $83 \%$ among females. While typing or using mouse $29.5 \%$ had their wrists in flexed position, $19.0 \%$ in extended position and $51.5 \%$ in neutral position.

Out of the 648 computer professionals, 85 had CTS (clinical diagnosis) with a prevalence of $13.1 \%$ (95\% CI, 10.5-15.7\%).The prevalence among males was $14.5 \%$ and among females $6.8 \%$ and the difference was statistically significant. CTS prevalence was higher in the age group above 30 compared to 20-30 years. In this study no one with a history of co-morbid conditions (diabetes mellitus, rheumatoid arthritis and thyroid disorders) had CTS (Table 2).

TABLE 2. Prevalence of Carpal Tunnel Syndrome as per Gender and Age

\begin{tabular}{|c|c|c|c|}
\hline & Prevalence (\%) & $95 \% \mathrm{Cl}$ & $P$ Value \\
\hline \multicolumn{4}{|l|}{ Gender } \\
\hline Male & 14.5 & $11.5-17.5$ & .03 \\
\hline Female & 6.8 & $2.2-11.4$ & - \\
\hline \multicolumn{4}{|l|}{ Age } \\
\hline$\leq 30$ years & 12.4 & $9.8-15.0$ & .05 \\
\hline$>30$ years & 22.7 & $10.3-35.1$ & - \\
\hline
\end{tabular}

Computer professionals with more than 8 years of computer work had statistically significant 
TABLE 3. Association Between Computer Work Characteristics and Carpal Tunnel Syndrome (CTS)

\begin{tabular}{|c|c|c|c|c|c|}
\hline & \multicolumn{2}{|c|}{ CTS } & \multirow[b]{2}{*}{ Crude OR } & \multirow[b]{2}{*}{$95 \% \mathrm{Cl}$} & \multirow[b]{2}{*}{$P$ Value } \\
\hline & Yes & No & & & \\
\hline \multicolumn{6}{|l|}{ 1. Years of computer work } \\
\hline$<4$ & 40 & 391 & 1.0 & - & - \\
\hline $4-8$ & 31 & 131 & 2.3 & $1.4-3.8$ & .0012 \\
\hline$>8$ & 14 & 41 & 3.3 & $1.7-6.6$ & .0006 \\
\hline \multicolumn{6}{|c|}{$\mathrm{X}^{2}$ for trend $17.8 ; P=.00002$} \\
\hline \multicolumn{6}{|c|}{ 2. Hours of computer work per day } \\
\hline$<8$ & 4 & 84 & 1.0 & - & - \\
\hline $8-12$ & 70 & 432 & 3.4 & $1.2-9.5$ & .020 \\
\hline$>12$ & 11 & 47 & 4.9 & $1.5-16.2$ & .009 \\
\hline \multicolumn{6}{|c|}{$\mathrm{X}^{2}$ for trend $7.2 ; P=.007$} \\
\hline \multicolumn{6}{|l|}{ 3. Job functions } \\
\hline Data entry & 30 & 214 & 1.0 & - & \\
\hline System administrator & 13 & 37 & 2.5 & $1.2-5.2$ & .01 \\
\hline Software developer & 18 & 125 & 1.0 & $0.6-1.9$ & .90 \\
\hline Others & 24 & 187 & 0.9 & $0.5-1.6$ & .80 \\
\hline \multicolumn{6}{|l|}{ 4. Hand position } \\
\hline Neutral & 39 & 295 & 1.0 & - & - \\
\hline Flexed or extended & 46 & 268 & 1.3 & $0.8-2.1$ & .30 \\
\hline \multicolumn{6}{|l|}{ 5. Smoking } \\
\hline No & 29 & 138 & 1.0 & - & - \\
\hline Yes & 56 & 425 & 1.6 & $1.0-2.6$ & .06 \\
\hline \multicolumn{6}{|l|}{ 6.Alcohol } \\
\hline No & 28 & 127 & 1.0 & - & - \\
\hline Yes & 57 & 436 & 1.7 & $1.1-2.8$ & .04 \\
\hline \multicolumn{6}{|l|}{ 7. Internet use (leisure time) } \\
\hline No & 29 & 268 & 1.0 & - & - \\
\hline Yes & 56 & 295 & 1.8 & $1.2-2.7$ & .03 \\
\hline \multicolumn{6}{|l|}{ 8. BMI grading } \\
\hline$<25$ & 60 & 396 & 1.0 & - & - \\
\hline$\geq 25$ & 25 & 167 & 1.0 & $0.6-1.6$ & 1.0 \\
\hline
\end{tabular}

Notes. BMI-Body Mass Index.

higher risk $(\mathrm{OR}=3.3)$ for $\mathrm{CTS}$ compared to those with less than 4 years. A dose response was observed with an increasing number of years of work showing higher risk for CTS and the test for linear trend was statistically significant. Similarly those who did computer work for more than $12 \mathrm{hrs}$ per day had significantly higher risk $(\mathrm{OR}=4.9)$ for CTS compared to those who worked for less than $8 \mathrm{hrs}$ per day. Dose response was observed and the test for linear trend was statistically significant (Table 3 ).

System administrators had 2.5 times greater risk for CTS compared to other types of job functions and this was statistically significant. Flexed or extended hand position had a higher risk for CTS compared to neutral position though this was not statistically significant (Table 3). Those who used alcohol on a regular basis had significantly higher risk $(\mathrm{OR}=1.7)$ for CTS. Smokers also had higher risk for CTS $(\mathrm{OR}=1.6)$, however statistically not significant. Higher BMI did not show higher risk for CTS.

Since age, gender, smoking, alcohol use and BMI are potential confounders, adjusted OR was found for years of computer work, hours of computer work per day and type of job function 
TABLE 4. Adjusted OR for Computer Work Characteristics and Carpal Tunnel Syndrome

\begin{tabular}{lccc}
\hline & Adjusted $\mathbf{O R}^{\boldsymbol{*}}$ & $\mathbf{9 5 \%} \mathbf{C l}$ & $\boldsymbol{P}$ Value \\
\hline $\begin{array}{l}\text { 1. Years of computer work } \\
\quad<4\end{array}$ & 1.0 & - & - \\
$\quad 4-8$ & 2.1 & $1.3-3.6$ & .004 \\
$\quad>8$ & 2.7 & $1.3-5.8$ & .01 \\
2. Hours of computer work per day & & & - \\
$\quad<8$ & 1.0 & - & .02 \\
$\quad 8-12$ & 3.6 & $1.3-10.3$ & .02 \\
$\quad>12$ & 4.4 & $1.3-14.9$ & \\
3. Job functions & & & .01 \\
$\quad$ Other job functions & 1.0 & - & - \\
$\quad$ System administrator & 2.4 & $1.2-4.8$ & .02 \\
4. Internet use (leisure time) & & & - \\
$\quad$ No & 1.0 & $1.2-2.7$ & \\
$\quad$ Yes & 1.7 & &
\end{tabular}

Notes. *-adjusted for age, gender, smoking, alcohol use and Body Mass Index.

with multiple logistic regression. Even after adjustment for age, gender, smoking, alcohol use and BMI, longer years of computer work, longer hours of computer work per day, the job of a system administrator and Internet use showed statistically significant higher risk for CTS (Table 4).

\section{DISCUSSION}

The prevalence of CTS among computer professionals based on clinical signs and symptoms is found to be as high as $13.1 \%$, which implies that almost 1 out of every 8 computer professional suffers from this condition. Very few studies on CTS prevalence based on clinical signs and symptoms have been done in general populations. These studies report population prevalence of CTS ranging from 3 to $6 \%$ only [22, 23, 24]. Compared to this, CTS prevalence of $13.1 \%$ among computer professionals may be considered as an important health problem in this occupation. Health care providers need to be aware of this and it is necessary to identify the risk factors for CTS among computer professionals and explore possible preventive measures.

Longer years of exposure as a computer professional and longer hours of computer work per day have been found to be risk factors for CTS even after adjusting for possible confounding by age, gender, smoking, alcohol use and BMI (Table 4). A test for a linear trend was also statistically significant (Table 3 ) for those risk factors exhibiting dose response for CTS. These findings implicate that a higher level of exposure to computer work results in higher risk for CTS.

System administrators are under greater work pressure and stress, constantly involved with typing and using a mouse, compared to other computer jobs and it was found that they were 2.4 times at greater risk for CTS even after controlling for possible confounding factors (Table 4). This once again implicates that a higher level of intensity of computer work results in higher risk for CTS.

All those findings strengthen the hypothesis that computer work is associated with CTS and reducing high levels of exposure to computer work may probably reduce risk for CTS. Similar findings have been reported by others. In a study done among 25,000 workers using VDT who were involved in data entry and mental arithmetic tasks, a physical symptoms score became higher with increasing duration of daily VDT use. Duration of daily VDT use was linearly related to the physical symptoms score [25]. Another study found that increasing daily work duration increased the probability of CTS risk among VDT operators [26]. 
Higher risk for CTS has been found when the wrist is kept in a flexed or extended position compared to a neutral position (Table 3). Though this higher risk is not statistically significant, it conforms to the biological plausibility, since carpal tunnel becomes narrower when the hand is kept flexed or extended at wrist joint compared to a neutral position [27]. This requires attention to ergonomics. Keeping the hand in a neutral position while working with a computer can be facilitated to a great extent by having a fully adjustable chair and a proper positioning of the keyboard and mouse. Creating awareness among computer professionals regarding keeping the hand in a neutral position is also important.

The use of the Internet during leisure time by computer professionals shows a statistically significant positive association with CTS even after controlling for possible confounding factors (Table 4). This could be attributed to a cumulative effect due to added exposure to computer work and due to an unergonomic working environment since most of them access the Internet at home.

In the general population, prevalence of CTS is higher among females than among males [16, 22]. This study among computer professionals has found higher prevalence of CTS among males. This may be because a higher proportion of males had $\geq 4$ years of computer work and $\geq 8$ hours of computer work per day than females and a higher proportion of males worked as system administrators.

This study is based on a sample of computer professionals, selected with simple random sampling with an optimal sample size from a heterogeneous source of computer professionals, with different types of job functions, varied years of computer work and hours of computer work per day, which to a great extent ensures generalization for the study among computer professionals.

The findings of this study implicate that CTS is an important musculoskeletal problem among computer professionals. CTS has been reported to be a painful condition with numbness and tingling in the hand and an important cause of work disability [23]. Hence it is important to make an early diagnosis of CTS among computer professionals based on symptoms and clinical examination to prevent progression to work disability. It is also important to study the related risk factors further and to implement suitable ergonomics measures and work regulations to alleviate much suffering and pain among those involved in this ever expanding occupation.

The subject of CTS is covered extensively in literature. This pertains mostly to CTS in occupations other than the computer profession. Similarly a lot of literature is available about computer professionals with reference to other occupational health problems like the computer vision syndrome, shoulder pain, neck pain, depression, etc. However there is not much literature available specifically pertaining to the prevalence of CTS among computer professionals or about risk factors for CTS among computer professionals. This study provides new information about both.

\section{REFERENCES}

1. Punnet L, Bergqvist U. Visual display unit work and upper extremity musculoskeletal disorders: a review of epidemiological findings (Ergonomic expert committee document No. 1). Stockholm, Sweden: National Institute for Working Life; 1997.

2. Jensen C, Finsen L, Sogaard K, Christensen H. Musculoskeletal symptoms and duration of computer and mouse use. Int J Ind Ergron 2002;30:265-75.

3. Jensen C, Ryholt CU, Burr H, Villadsen E, Christensen H. Work-related psychosocial, physical and individual factors associated with musculoskeletal symptoms in computer users. Work Stress. 2002;16(2):107-20.

4. Bernard B, Sauter S, Fine L, Petersen M, Hales T. Job task and psychosocial risk factors for work-related musculoskeletal disorders among news paper employees. Scand J Work Environ Health. 1994; 20(6):417-26.

5. Karlqvist LK, Hagberg $M$, Koster $M$, Wenemark M, Anell R. Musculoskeletal symptoms among computer-assisted design (CAD) operators and evaluation of a selfassessment questionnaire. Int $\mathrm{J}$ Occup Environ Health. 1996;2(3):185-94. 
6. Fogleman M, Lewis RJ. Factors associated with self-reported musculoskeletal discomfort in video display terminal (VDT) users. Int J Ind Ergon. 2002;29:311-8.

7. Demure B, Luippold RS, Bigelow C, Ali D, Mundt KA, Liese B. Video display terminal workstation improvement program: 1. Baseline associations between musculoskeletal discomfort and ergonomic features of workstations. J Occup Environ Med. 2000;42(8):783-91.

8. Karlqvist L. Avoid the mouse trap! Musculoskeletal injuries can be reduced by placing the mouse within shoulder space. Lakartidningen. 1998;95(36):3768-71. In Swedish.

9. Bergqvist U, Wolgast E, Nilsson B, Voss M. Musculoskeletal disorders among visual display terminal workers: individual, ergonomic, and work organizational factors. Ergonomics. 1995;38(4):763-76.

10. Aarås A, Fostervold KI, Ro $\mathrm{O}$, Thoresen M, Larsen S. Postural load during VDU work: a comparison between various work postures. Ergonomics. 1997;40(11):1255-68.

11. Karlqvist LK, Bernmark E, Ekenvall L, Hagberg M, Isaksson A, Rosto T. Computer mouse position as a determinant of posture, muscular load and perceived exertion. Scand J Work Environ Health. 1998;24(1):62-73.

12. Psihogios JP, Sommerich CM, Mirka GA, Moon SD. A field evaluation of monitor placement effects in VDT users. Appl Ergon. 2001;32(4):313-25.

13. Tittiranonda P, Burastero S, Rempel D. Risk factors for musculoskeletal disorders among computer users. Occup Med. 1999;14(1):17-38, iii.

14. Seppälä P. Experience of stress, musculoskeletal discomfort, and eyestrain in computer-based office work: a study in municipal workplaces. Int J Hum Comput Interact. 2001;13:279-304.

15. Marcus M, Gerr F. Upper extremity musculoskeletal symptoms among female office workers: associations with video display terminal use and occupational psychosocial stressors. Am J Ind Med. 1996;29(2):161-70.

16. Phillip E, Wright II. Carpal tunnel syndrome and ulnar tunnel syndromes and stenosing tenosynovitis. In: Canale ST, editor. Campbell's operative orthopaedics. 9th ed. St. Louis, MO, USA: Mosby; 1998. p. 3685-701.

17. Lewis LC, Mireles DZ. Occupational health hazard: carpal tunnel syndrome. Semin Perioper Nurs. 1997;6(2):105-10.

18. Murata K, Araki S, Okajima F, Saito Y. Subclinical impairement in the median nerve across the carpal tunnel among female VDT operators. Int Arch Occup Environ Health. 1996;68(2):75-9.

19. Stevens JC, Witt JC, Smith BE, Weaver AL. The frequency of carpal tunnel syndrome in computer users at a medical facility. Neurology. 2001;56(11):1568-70.

20. Ecstasia. Dorland's illustrated medical dictionary. 27th ed. Philadelphia, PA, USA: Saunders; 1998.

21. Gorsche RG, Wiley JP, Renger RF, Brant RF, Gemer TY, Sasyniuk TM. Prevalence and incidence of carpal tunnel syndrome in a meat packaging plant. Occup Environ Med. 1999;56:417-22.

22. de Krom MC, Knipschild PG, Kester AD, Thijs CT, Boekkooi PF, Spaans F. Carpal tunnel syndrome-prevalence in general population. J Clin Epidemiol. 1992;45(4):373-6.

23. Atorshi I, Gummenson C, Johnsson R, Ornstein E, Ranstam J, Rosen I. Prevalence of carpal syndrome in a general population. JAMA. 1999;282(2):153-8.

24. Papanicolaou GD, Mac Cabe SJ, Firell J. The prevalence and characteristics of nerve compression symptoms in the general population. J Hand Surg (Am). 2001;26(3):460-6.

25. Nakazawa T, Okubo $Y$, Suwazono $Y$, Kobayashi E, Komine S, Kato N, et al. Association between duration of daily VDT use and subjective symptoms. Am J Ind Med. 2002;42(5):421-6.

26. Matias AC, Salvendy G, Kuczek T. Predictive models of carpal tunnel syndrome causation among VDT operators. Ergonomics. 1998;41(2):213-26.

27. Robert D. Beckenbaugh. Carpal tunnel syndrome. In: Cooney WP, Linscheid RL, Dobyns JH, editors. The wrist diagnosis and operative treatment. St. Louis, MO, USA: Mosby; 1998. p. 1197-233. 